\title{
Stabilization of collagen nanofibers with L-lysine improves the ability of carbodiimide cross-linked amniotic membranes to preserve limbal epithelial progenitor cells
}

\author{
This article was published in the following Dove Press journal: \\ International Journal of Nanomedicine \\ 5 November 2014 \\ Number of times this article has been viewed
}

\author{
Jui-Yang Lai ${ }^{1-3}$ \\ Pei-Ran Wang' \\ Li-Jyuan Luo' \\ Si-Tan Chen' \\ 'Institute of Biochemical and \\ Biomedical Engineering, ${ }^{2}$ Biomedical \\ Engineering Research Center, \\ ${ }^{3}$ Molecular Medicine Research Center, \\ Chang Gung University, Taoyuan, \\ Taiwan, Republic of China
}

\begin{abstract}
To overcome the drawbacks associated with limited cross-linking efficiency of carbodiimide modified amniotic membrane, this study investigated the use of L-lysine as an additional amino acid bridge to enhance the stability of a nanofibrous tissue matrix for a limbal epithelial cell culture platform. Results of ninhydrin assays and zeta potential measurements showed that the amount of positively charged amino acid residues incorporated into the tissue collagen chains is highly correlated with the L-lysine-pretreated concentration. The cross-linked structure and hydrophilicity of amniotic membrane scaffolding materials affected by the lysine molecular bridging effects were determined. With an increase in the L-lysine-pretreated concentration from 1 to $30 \mathrm{mM}$, the cross-linking density was significantly increased and water content was markedly decreased. The variations in resistance to thermal denaturation and enzymatic degradation were in accordance with the number of cross-links per unit mass of amniotic membrane, indicating L-lysine-modulated stabilization of collagen molecules. It was also noteworthy that the carbodiimide cross-linked tissue samples prepared using a relatively high L-lysine-pretreated concentration (ie, $30 \mathrm{mM}$ ) appeared to have decreased light transmittance and biocompatibility, probably due to the influence of a large nanofiber size and a high charge density. The rise in stemness gene and protein expression levels was dependent on improved cross-link formation, suggesting the crucial role of amino acid bridges in constructing suitable scaffolds to preserve limbal progenitor cells. It is concluded that mild to moderate pretreatment conditions (ie, 3-10 mM L-lysine) can provide a useful strategy to assist in the development of carbodiimide cross-linked amniotic membrane as a stable stem cell niche for corneal epithelial tissue engineering.
\end{abstract}

Keywords: amniotic membrane, L-lysine-pretreated concentration, collagen nanofiber stabilization, limbal progenitor cell preservation, corneal epithelial tissue engineering

\section{Introduction}

It has long been recognized that the extracellular matrix is an important component providing a framework for cell-to-cell communication and cellular organization. ${ }^{1}$ The human amniotic membrane (AM) is known to be one of the most prevalent natural matrices with potential applications in corneal regenerative medicine. ${ }^{2}$ A recent review paper by Mamede et al has emphasized that the unique structural and functional features of AM materials are being utilized for the development of clinically successful therapeutic strategies, particularly for ocular surface reconstruction. ${ }^{3}$ Cultivation and transplantation of limbal epithelial cells (LECs) on AM carriers has proven to be effective in treating patients with unilateral corneal stem cell deficiency. ${ }^{4}$ However, given that the collagen nanofibers constitute the architectural framework of the AM,
Institute of Biochemical and Biomedical

Engineering, Chang Gung University,

259, Wen-Hwa First Road,

Kwei-Shan, Taoyuan, Taiwan 33302

Republic of China

$\mathrm{Tel}+886321$ I 8800 extension 3598

Fax+88632II 8668

Email jylai@mail.cgu.edu.tw submit your manuscript | www.dovepress.com

Dovepress

http://dx.doi.org// 0.2147/IJN.S69689
International Journal of Nanomedicine 20|4:9 5I I7-5।30

5117

(c) (i) (5) 2014 Lai et al. This work is published by Dove Medical Press Limited, and licensed under Creative Commons Attribution - Non Commercial (unported, v3.0)

LY LCense. The full terms of the License are available at http://creativecommons.org/licenses/by-nc/3.0/. Non-commercial uses of the work are permitted without any further permission from Dove Medical Press Limited, provided the work is properly attributed. Permissions beyond the scope of the License are administered by Dove Medical Press Limited. Information on how to request permission may be found at: http://www.dovepress.com/permissions.php 
this biological tissue material may exhibit progressive degradation in vivo after its exposure to endogenous matrix metalloproteinases (MMPs). In certain corneal diseases with increased tissue collagenase activity, ${ }^{5}$ disintegration of AM transplants at the ocular surface can be accelerated, depending on the level of inflammation. It has been documented that poor biostability of an AM graft contributes to its early detachment during wound healing. ${ }^{6}$ Therefore, surgical failure is probably caused by excessive proteolytic degradation of the AM matrices.

To circumvent these drawbacks, there are obvious incentives to develop a powerful strategy with special emphasis on improved molecular stability of AM. In order to serve as a limbal stem cell niche, the AM collagen was modified to construct a cross-linked molecular biopolymer chain network. Glutaraldehyde is a commonly used chemical cross-linker that has high efficiency in the stabilization of collagenous biomaterials. Fujisato et al have shown that AM matrices cross-linked with glutaraldehyde are resistant to digestion by collagenase. ${ }^{7}$ More recently, we also studied the effect of glutaraldehyde cross-linking on the nanostructure of AM materials and found that the cross-linking chemistry-mediated alteration in fibrillar collagen is critical to determining the performance of biological tissue scaffolds for maintenance of stemness in LECs. ${ }^{8}$ The enhanced collagen molecular stability of glutaraldehyde-treated AM is positively correlated with the amount of cross-linkers in the reaction system. ${ }^{9}$ Nevertheless, a method involving chemical modification of AM with glutaraldehyde probably raises risk of safety, especially when the extent of cross-linking exceeds a critical value. ${ }^{8,9}$ In comparison with a non-zero-length cross-linker such as glutaraldehyde, 1-ethyl-3-(3-dimethyl aminopropyl) carbodiimide hydrochloride (EDC) is a zero-length cross-linker that activates carboxylic acid groups and then forms peptide linkages with the amino groups of proteinaceous matrices. ${ }^{10,11}$ Since the modification with carbodiimide does not introduce foreign structures into the biomaterial network, this crosslinking technique is considered more biocompatible. ${ }^{12}$ In our laboratory, the EDC/N-hydroxysuccinimide (NHS) has been previously used for the development of chemically cross-linked AM materials. ${ }^{13}$ However, with carbodiimide treatment for a longer duration (ie, 4 hours), the AM samples showed significant weight loss after 4 weeks of incubation in MMPs, suggesting low cross-linking efficiency of biological tissues. ${ }^{14}$

It is highly desirable to generate cross-links sufficient to provide protective barriers shielding the proteinaceous matrix from enzymatic attack while maintaining its biocompatibility.
In the research field of chemical modification of collagen, amino acids have been investigated as cross-linking bridges to improve the biological stability of materials. Ma et al have shown that the presence of lysine (ie, a basic amino acid) is able to assist the carbodiimide cross-linking of porous collagen scaffolds, leading to enhancement of resistance to cleavage by protease. ${ }^{15}$ In contrast, addition of glycine (ie, a neutral amino acid) or glutamic acid (ie, an acidic amino acid) into the cross-linking reaction system has no significant and negative influence on collagen stability, respectively, indicating the crucial role of amino acid type in modulation of the physicochemical properties of carbodiimide cross-linked collagenous biomaterials. Recently, Usha et al demonstrated that incorporation of L-lysine in EDC/NHS cross-linking is a very effective way to favor the molecular and phase structure and self-assembly process of collagen nanofibrils. ${ }^{16}$ The possibility of induction of cross-links in the presence of L-lysine can be attributed to the closer proximity of the collagen molecules, exposing sufficient reactive groups. In light of these earlier studies, it would be interesting to determine whether pretreatment of AM collagen molecules with L-lysine affects the properties of chemically cross-linked biological tissue scaffolds for LEC cultivation. To the best of our knowledge, the effects of the L-lysine-pretreated concentration on EDC/ NHS cross-linking of AM collagenous biomaterials have not been reported to date.

The purpose of this investigation was to enhance the collagen nanofiber stability of an AM matrix and to improve its ability to serve as a limbal stem cell niche. The AM materials were subjected to L-lysine pretreatment and carbodiimide chemistry to increase the formation of cross-links between polypeptide chains in the fiber. Biological tissue samples were incubated with L-lysine at varying concentrations and were evaluated by ninhydrin assays in order to study changes in free amino group content. The zeta potential was also measured as a function of the L-lysine-pretreated concentration. After further chemical modification of the L-lysine-pretreated AM with EDC/NHS, cross-linking density and water content measurements were performed to examine how pretreatment with L-lysine might affect the extent of cross-linking. In addition, the stability of collagen nanofibers exposed to thermal denaturation and enzymatic digestion was determined by differential scanning calorimetry and in vitro degradation tests, respectively. Light transmittance measurements were used to assess the optical properties of the chemically modified collagenous tissues. After exposure of human corneal epithelial cell cultures to the biological test materials, the pattern of cell growth was monitored by phase-contrast microscopy 
and detection of mitochondrial dehydrogenase activity. Quantitative real-time reverse transcription polymerase chain reaction and Western blot analyses were conducted on the LEC cultures to explore cell stemness associations with collagen nanofiber stability for the L-lysine-pretreated and EDC/ NHS cross-linked AM substrates. A profound understanding of cell-material interactions is imperative to gain insight into the cross-linking effects via amino acid bridges on the biocompatibility and cell culture performance of chemically modified AM matrices.

\section{Materials and methods Materials}

This work followed the tenets of the Declaration of Helsinki involving human subjects and received approval from our institutional review board. Human AM tissue (ie, the innermost layer of the placental membrane) was obtained with informed consent at the time of elective cesarean section from mothers when human immunodeficiency virus, syphilis, and hepatitis $\mathrm{B}$ and $\mathrm{C}$ had been excluded by serological tests. Separation of the AM was performed by cutting the tissue samples approximately $2 \mathrm{~cm}$ from the placental disc. The average thickness of the AM samples was about $100 \mu \mathrm{m}$. EDC, L-lysine, ninhydrin reagent, MMP-1 (EC 3.4.24.7), and MMP-9 (EC 3.4.24.35) were obtained from Sigma-Aldrich (St Louis, MO, USA). N-hydroxysuccinimide (NHS) was supplied by Acros Organics (Geel, Belgium). Balanced salt solution (BSS, $\mathrm{pH}$ 7.4) was purchased from Alcon Laboratories (Fort Worth, TX, USA). Dulbecco's Modified Eagle's Medium and TRIzol reagent were purchased from Gibco-BRL (Grand Island, NY, USA). The 24-well tissue culture polystyrene plates (Falcon 353047 ) and cell culture inserts (Falcon 3095) were purchased from Becton Dickinson Labware (Franklin Lakes, NJ, USA). All other chemicals were of reagent grade and were used as received without further purification.

\section{Preparation of chemically cross-linked amniotic membranes}

The AM samples were aseptically obtained and stored at $-80^{\circ} \mathrm{C}$ in Dulbecco's Modified Eagle's Medium containing $50 \%$ glycerol. ${ }^{17}$ After incubation with $0.02 \%$ ethylenediaminetetraacetic acid at $37^{\circ} \mathrm{C}$, the $\mathrm{AM}$ was scraped to remove the amniotic epithelial cells. Prior to chemical cross-linking, $500 \mathrm{mg}$ of AM material was immersed in $30 \mathrm{~mL}$ of MES buffer containing 0-30 mM L-lysine for 6 hours. In this work, biological tissue pretreated with a L-lysine concentration of $30 \mathrm{mM}$ was designated as Lys30.
The ninhydrin assay was used as described previously to determine the amount of free amino groups in each AM sample. ${ }^{18}$ After reaction of the AM samples with ninhydrin reagent, the optical absorbance of the test solution was recorded using an ultraviolet-visible spectrophotometer (Thermo Scientific, Waltham, MA, USA) at $570 \mathrm{~nm}$. Glycine at various known concentrations was used as the standard. The amount of free amino groups in the AM is proportional to the optical absorbance of the solution. The free amino group content of the sample is expressed as the number of amine groups present per 1,000 amino acid residues. The results were the average of four independent measurements. In this study, the free amino group content of AM collagen was around 34 per 1,000 amino acid residues prior to pretreatment with L-lysine and carbodiimide cross-linking.

The zeta potential of various test samples was quantified with the streaming potential method. ${ }^{19}$ An electrokinetic analyzer (BI-EKA; Anton Paar, Austria) located at the Center for Emerging Material and Advanced Devices at National Taiwan University (Taipei, Taiwan) was utilized to determine the charge on the membrane surface. After equilibrating AM in $1 \mathrm{mM} \mathrm{KCl}$ for 2 hours, the zeta potential measurements were carried out using $1 \mathrm{mM} \mathrm{KCl}$ as the electrolyte solution. The $\mathrm{pH}$ of the solution was adjusted to 7.4. The results were averaged on four independent runs.

After pretreatment of AM collagen with L-lysine, EDC and NHS were added to this buffer solution simultaneously to catalyze the formation of zero-length covalent cross-links between protein molecules. During the cross-linking process, the cross-linker concentration was fixed at $0.05 \mathrm{mmol} \mathrm{EDC} /$ mg AM and the EDC to NHS molar ratio was 5:1. After allowing the cross-linking reaction to proceed at $25^{\circ} \mathrm{C}$ for 3 hours, the membrane samples were thoroughly washed with deionized water to remove excess EDC and urea byproduct.

\section{Cross-linking density measurements}

The cross-linked structure of the chemically modified AM was analyzed in order to study the degree of cross-linking and the average molecular weight of the polymer chains between two consecutive junctions. ${ }^{20}$ In brief, after immersion of the membrane samples in deionized water for 12 hours at $25^{\circ} \mathrm{C}$, the mechanical properties were determined using an Instron Mini 44 universal testing machine (Canton, MA, USA). The density of test specimens was then determined by the specific gravity bottle method. A graph of $\sigma$ against $\left(\alpha-\alpha^{-2}\right)$ would be a straight line with the slope giving $R T \rho V^{1 / 3} / M_{\mathrm{c}}$, where $\sigma$ is the force per unit area of the swollen unstretched 
sample; $\alpha$ is the extension ratio; $R$ is the gas constant; $T$ is the absolute temperature; $\rho$ is the density of the sample; $V$ is the volume fraction; and $M_{\mathrm{c}}$ is the average molecular weight of the chains between cross-links. The number of cross-links per unit mass was $\left(2 M_{\mathrm{c}}\right)^{-1}$. The results are the average of five independent measurements.

\section{Water content measurements}

Before testing, the AM samples were first dried to a constant weight $\left(W_{\mathrm{i}}\right)$ in vacuo. After 6 hours of immersion in deionized water at $37^{\circ} \mathrm{C}$ with reciprocal shaking $(50 \mathrm{rpm})$ in a thermostatically controlled water bath, the swollen membranes were weighed $\left(W_{\mathrm{s}}\right)$. The equilibrium water content $(\%)$ of the test sample was defined by $\left(\left(W_{\mathrm{s}}-W_{\mathrm{i}}\right) / W_{\mathrm{s}}\right) \times 100$ as described previously. ${ }^{21}$ The results are averaged on five independent runs.

\section{Differential scanning calorimetry}

The shrinkage temperature of the chemically modified AM was investigated using a DSC 2010 differential scanning calorimeter (TA Instruments, New Castle, DE, USA). ${ }^{13}$ Programmed heating was carried out at $5^{\circ} \mathrm{C}$ per minute in the temperature range of room temperature to $110^{\circ} \mathrm{C}$ with an empty aluminum pan as the reference probe. Resistance against thermal denaturation (ie, shrinkage temperature) was measured as the onset value of the occurring endothermic peak. The results are averaged on four independent runs.

\section{In vitro degradation tests}

Each test AM $\left(1 \times 1 \mathrm{~cm}^{2}\right)$ was first dried to a constant weight $\left(W_{\mathrm{i}}\right)$ in vacuo. The extent of degradation was measured by immersing the material samples in $1 \mathrm{~mL}$ of BSS containing $12 \mu \mathrm{g}$ of MMP-1 or MMP-9. During 4 weeks of incubation at $37^{\circ} \mathrm{C}$ with reciprocal shaking $(50 \mathrm{rpm})$ in a thermostatically controlled water bath, the degradation medium was replaced weekly with fresh buffer solution containing the same concentration of enzyme. The dry weight $\left(W_{\mathrm{d}}\right)$ of the degraded samples was determined following further drying in vacuo. The percentage of weight remaining was calculated as $\left(W_{\mathrm{d}} / W_{\mathrm{i}}\right) \times 100$, as described previously. ${ }^{22}$ The results are the average of four independent measurements.

\section{Light transmittance measurements}

The average optical transmittance of the AM samples following equilibrium swelling in BSS was measured using an ultraviolet-visible spectrophotometer (Thermo Scientific) as described previously. ${ }^{23}$ The spectral range was chosen between $400 \mathrm{~nm}$ and $700 \mathrm{~nm}$. During operation, the reference sample is the AM holder only, and the test sample consists of the holder with the AM in place. Results are the average of three independent measurements.

\section{Cell viability assays}

An HCE-2 cell line (ATCC CRL-11135) was obtained from the American Type Culture Collection (Manassas, VA, USA). The cells were cultured according to a method described previously. ${ }^{14}$ The HCE-2 cells were plated at a density of $5 \times 10^{4}$ cells/well in 24 -well plates. Each well of the 24-well plate was then divided into two compartments using cell culture inserts. ${ }^{24}$ A sterilized AM sample (0.2 g) was placed into the inserts to examine the corneal epithelial cultures. After 3 days of incubation, the inserts and membranes were removed to determine cell growth. Cells not in contact with the material samples served as controls.

Cell morphology was observed by phase-contrast microscopy (Nikon, Melville, NY, USA), as described previously. ${ }^{25}$ Cell viability was estimated using the CellTiter 96 Aqueous Non-Radioactive Cell Proliferation MTS Assay (Promega, Madison, WI, USA), in which MTS tetrazolium compound is bioreduced by cells into a colored formazan. ${ }^{26}$ Data for absorbance readings at $490 \mathrm{~nm}$ were then measured using a Multiskan Spectrum Microplate spectrophotometer (Thermo Lab Systems, Vantaa, Finland). All experiments were performed in quadruplicate. The results are expressed as relative MTS activity as compared with control groups.

\section{Stemness gene and protein expression analyses}

The rabbit LECs were isolated and cultured according to a method described previously. ${ }^{8}$ Cells with a density of $5 \times 10^{4}$ cells/well were seeded into 24-well tissue culture polystyrene plates and maintained in regular growth medium served as control groups. After incubation with various sterilized AM samples at $37^{\circ} \mathrm{C}$ for 5 days, total RNA was isolated from the cells using TRIzol reagent as described elsewhere. ${ }^{27}$ Reverse transcription of the extracted RNA ( $1 \mu \mathrm{g}$ ) was carried out using ImProm-II (Promega) and Oligo $(\mathrm{dT})_{15}$ primers (Promega). The primers used to amplify the rabbit p63 complementary DNA were 5'-TCTGGACTATTTCACGACCCAG-3' (sense) and 5'-AGATGGGGAGGTGAGGAAAAG-3' (antisense), and those used to amplify the rabbit ABCG2 were 5'-GAGAGCTGGGTCTGGAAAAAGT-3' (sense) and 5'-ATTCTTTTCAGGAGCAGAAGGA-3' (antisense). The sequences of the primer pair used to amplify the internal control complementary DNA, glyceraldehyde-3-phosphate 
dehydrogenase, were 5'-TTGCCCTCAATGACCACTTTG-3' (sense) and 5'-TTACTCCTTGGAGGCCATGTG-3' (antisense). Quantitative real-time reverse transcription polymerase chain reaction was performed on a Light-Cycler instrument (Roche Diagnostics, Indianapolis, IN, USA) with FastStart DNA Master SYBR Green I reagent (Roche Diagnostics). Each sample was determined in quadruplicate. The gene expression results were normalized to the level of glyceraldehyde-3-phosphate dehydrogenase mRNA.

For Western blot analyses, the cells from each group were lysed as described previously. ${ }^{28}$ Proteins $(50 \mu \mathrm{g}$ of protein per lane) was separated by sodium dodecyl sulfate polyacrylamide gel electrophoresis in $10 \%$ polyacrylamide gel. The gels were then transferred to polyvinylidene difluoride membranes and incubated with anti-ABCG2 (1:1,000; Santa Cruz Biotechnology, Santa Cruz, CA, USA) primary antibodies and secondary antibodies conjugated to horseradish peroxidase (1:5,000; Chemicon International, Temecula, CA, USA) as described elsewhere. ${ }^{14}$ SuperSignal West Pico chemiluminescent substrate (Pierce, Rockford, IL, USA) was used for detection. Incubation with anti-alpha-tubulin (1:2,000; Abcam, Cambridge, MA, USA) was used for the loading controls. ABCG2 protein bands were analyzed by densitometry using Image J software. Results are the average of four independent measurements.

\section{Statistical analysis}

The results are expressed as the mean \pm standard deviation. Comparative studies of means were performed using one-way analysis of variance. Statistical significance was accepted at $P<0.05$.

\section{Results and discussion Preparation of chemically cross-linked amniotic membranes}

In clinical surgery, AM is an important graft material and has been widely used for healing of skin wounds, vaginal reconstruction, and pericardial closure. ${ }^{29} \mathrm{~A}$ review paper by Niknejad et al has summarized the research on the properties of AM and its potential use in tissue engineering. ${ }^{30}$ However, due to their insufficient biostability, AM matrices should be reinforced by chemical cross-linking. Our previous research has shown that the corneal surface can be reconstructed by ex vivo expanded autologous rabbit LECs cultured on carbodiimide cross-linked AM. ${ }^{13}$ The ability of chemically modified biological tissues to preserve keratinocyte progenitor cells is confirmed by immunoconfocal microscopy. More recently, LEC cultures on EDC/NHS-treated AM with a greater extent of cross-linking were found to exhibit enhanced stemness. ${ }^{14}$ These encouraging results motivated us to produce more stabilized AM matrices in this work.

As reported in the literature, L-lysine (a natural substance of the building blocks of protein molecules) has been studied for a variety of applications. Jezova et al demonstrated that treatment with L-lysine and L-arginine may have modulatory and anxiolytic effects on neuroendocrine activation during psychosocial stress in humans. ${ }^{31}$ Fujiwara et al have shown that cross-linked chitosan resin chemically modified with L-lysine can be used for adsorption of precious metal ions, such as gold, palladium, and platinum, from aqueous solutions. ${ }^{32} \mathrm{Li}$ et al examined the feasibility of using lysine as a cross-linker to induce self-assembly of gold nanoparticles on indium tin oxide glass and found that the molecular bridging effect of lysine and zwitterion-mediated interactions may occur at different acidic $\mathrm{pH}$ values. ${ }^{33}$ In our laboratory, collagen nanofiber-based AM materials have been chemically cross-linked by exogenous carbodiimide. ${ }^{8,13,14}$ However, a technique involving use of EDC/NHS to catalyze the formation of zero-length covalent cross-links between protein molecules allows only limited cross-linking. Herein, we investigated further use of lysine as a cross-linking bridge to enhance the EDC/NHS cross-linking efficiency of AM collagen while maintaining its biocompatibility. It was hypothesized that this would improve the formation of covalent cross-linkages imposed by L-lysine, thereby facilitating the stability of this cross-linked biological tissue scaffold as an LEC culture platform. Prior to their modification with carbodiimide chemistry, the AM matrices were incubated in buffer containing L-lysine for 6 hours.

\section{Determination of free amino group content}

Figure 1A shows the results for ninhydrin assays in various AM samples. In the groups without L-lysine pretreatment, the free amino group content was determined to be $33.8 \pm 1.0$ per 1,000 amino acid residues. This finding supports the report by Olde Damink et al who demonstrated that the free amino group content of dermal sheep collagen was 34 per 1,000 amino acid residues. ${ }^{34}$ On increasing the L-lysinepretreated concentration from 1 to $30 \mathrm{mM}$, the amount of free amino groups in the AM collagen increased $(P<0.05)$ significantly. It has been documented that treatment of tendon collagen fibers with L-lysine prior to chemical cross-linking allows incorporation of additional amino groups into the biomaterials. ${ }^{16}$ The present data are compatible with earlier observations, and further suggest that L-lysine concentration 
A

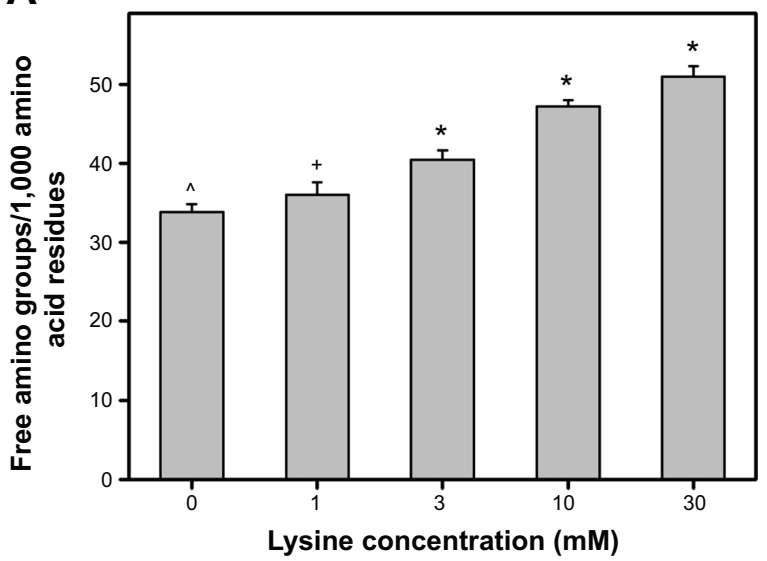

B

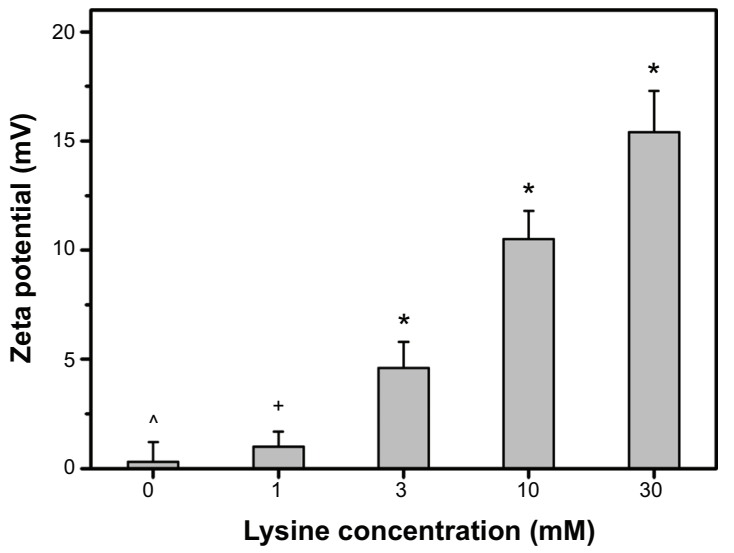

Figure I (A) Free amino group content and (B) zeta potential of amniotic membrane as a function of L-lysine-pretreated concentration. Values are shown as the mean \pm standard deviation $(n=4)$.

Notes: ${ }^{*} P<0.05$ versus all groups; ${ }^{\wedge} P<0.05$ versus all groups except I mM; ${ }^{+} P<0.05$ versus all groups except $0 \mathrm{mM}$.

plays an important role in the free amino group content of tissue collagen. During the pretreatment process, a large amount of L-lysine molecules may have an enhanced ability to become incorporated into AM collagen nanofibers, probably due to the increased collision frequency between tropocollagen molecules and foreign amino acid residues.

\section{Zeta potential measurements}

Given that lysine carries a positive charge, zeta potential measurements are also performed to confirm the success of L-lysine pretreatment of tissue collagen. Figure 1B shows the zeta potential results for various AM samples quantified by the streaming potential method. In the groups without L-lysine pretreatment, the zeta potential was $0.3 \pm 0.9 \mathrm{mV}$. $\mathrm{AM}$ is known to be composed of collagen molecules that have an isoelectric point of about 7.8. ${ }^{35}$ Given that this protein carries a net positive charge at a $\mathrm{pH}$ below its isoelectric point, native AM samples may have a slightly positive zeta potentials in a neutral buffer with $\mathrm{pH} 7.4$ (ie, physiological $\mathrm{pH})$. After incorporation of additional amino groups into the AM collagen nanofibers, all the L-lysine-pretreated biological tissue membranes remained positively charged. In the Lys 1 groups, the zeta potential was $1.0 \pm 0.7 \mathrm{mV}$, which was significantly lower than that of the Lys3 $(4.6 \pm 1.2 \mathrm{mV})$, Lys10 $(10.5 \pm 1.3 \mathrm{mV})$, and Lys30 $(15.4 \pm 1.9 \mathrm{mV})$ groups $(P<0.05)$. It was also noted that an increased zeta potential value was positively correlated with the L-lysine-pretreated concentration. Our results indicate that the presence of a large amount of positively charged amino acid residues can enhance the surface charge density of the AM scaffold, verifying high-level incorporation of amino groups into the tissue collagen.

\section{Cross-linking density measurements}

According to our recent observations, chemical cross-linkermediated alteration in the nanofibrous structure of AM scaffolds may be linked to the formation of cross-links between or within the collagen molecules. ${ }^{9}$ Therefore, this study paid attention to the analysis and understanding of the cross-linked structure of AM materials modified with carbodiimide. The effects of lysine-assisted EDC/NHS cross-linking of AM on its cross-linking density have yet to be reported in the literature. Here, the cross-linking density is expressed as number of cross-links $/ \mathrm{mol}$ wt $10^{5}$. The number of cross-links per unit mass of AM as a function of L-lysine-pretreated concentration is shown in Figure 2A. In the Lys0 groups, the number of cross-links per unit mass of EDC/NHS-modified tissue collagen matrix was $8.34 \pm 0.25$. This was not significantly different from those of the Lys1 (8.81 \pm 0.29$)$ groups $(P>0.05)$, indicating that the amount of amino groups incorporated into the AM scaffolds was insufficient to build up the reinforced cross-linked structure. However, when the L-lysinepretreated concentration was increased to $3 \mathrm{mM}$, the number of cross-links per unit mass of EDC/NHS-modified tissue collagen matrix was $10.24 \pm 0.17$. Furthermore, in the range of 3-30 mM, the cross-linking density values significantly increased with increasing L-lysine-pretreated concentration $(P<0.05)$. These findings suggest that the amount of crosslinks formed between the AM collagen chains is greatly affected by the presence of additional amino groups in the nanofibrous tissue matrices.

\section{Water content measurements}

Water content is another useful parameter for evaluation of the extent of cross-linking of protein-based biomaterials 
A

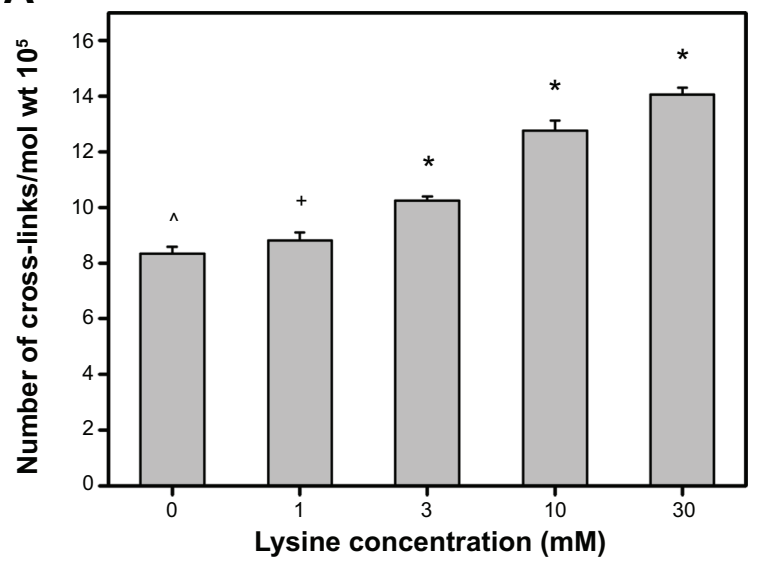

B

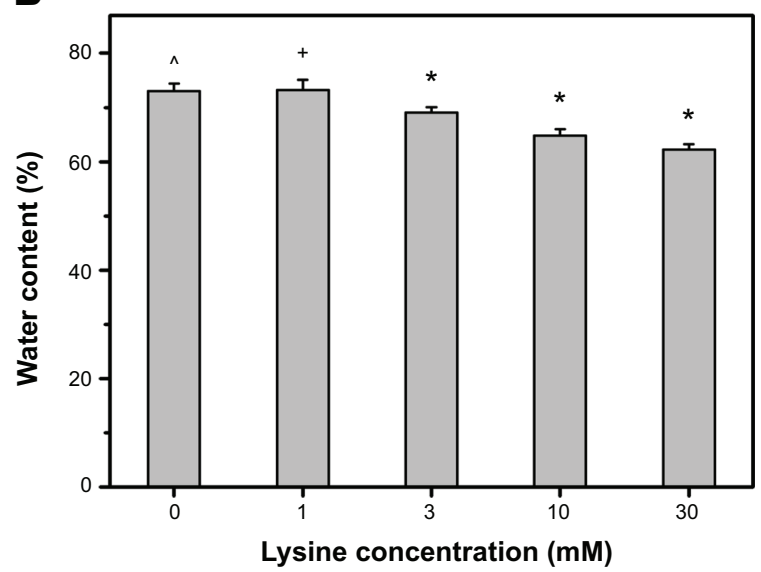

Figure 2 (A) Number of cross-links per unit mass and (B) equilibrium water content of amniotic membrane as a function of L-lysine-pretreated concentration. Values are shown as the mean \pm standard deviation $(n=5)$.

Notes: $* P<0.05$ versus all groups; ${ }^{\wedge} P<0.05$ versus all groups except I mM; ${ }^{+} P<0.05$ versus all groups except $0 \mathrm{mM}$.

because of their high water absorption and retention capacity. ${ }^{23,36}$ Here, the role played by amino acid bridges in the determination of EDC/NHS cross-linking efficiency of AM collagen nanofibers was analyzed. Figure 2B shows the equilibrium water content of AM samples as a function of L-lysine-pretreated concentration. After immersion in deionized water at $37^{\circ} \mathrm{C}$ for 6 hours, the carbodiimide cross-linked biological tissues from the Lys0 groups had an equilibrium water content of $73.0 \% \pm 1.4 \%$. It has been reported that carbodiimide cross-linking is a process that can chemically link biopolymer chains and reduce the water uptake capacity of these materials. ${ }^{37}$ We have demonstrated that at the same cross-linker concentration (ie, $0.05 \mathrm{mmol}$ EDC/mg AM), 2-4 hours of cross-linking treatment yields AM scaffolds with an equilibrium water content ranging from $75.9 \%$ to $67.5 \%{ }^{14}$ This finding supports those of the present study, ie, that the level of hydration of collagen fibers in the biological materials is reasonable after cross-linking with carbodiimide for 3 hours. The equilibrium water content in the Lys3, Lys10, and Lys30 groups was $69.1 \% \pm 1.0 \%$, $64.8 \% \pm 1.2 \%$, and $62.2 \% \pm 1.0 \%$, respectively. These values showed statistically significant differences $(P<0.05)$, suggesting that pretreatment with a large amount of L-lysine molecules may increase the hydrophobicity of chemically modified AM collagen.

\section{Differential scanning calorimetry}

Collagen consists of triple-helical tropocollagen molecules that are stabilized mainly by hydrogen bonding and van der Waals interactions. ${ }^{38}$ After glutaraldehyde cross-linking of AM scaffolds, the formation of cross-links within the tissue collagen matrix is able to prevent thermal denaturation, which is a phenomenon of transformation of the welldefined folded protein structure. ${ }^{9}$ We have also determined that the increment in shrinkage temperature associated with improved resistance against thermal denaturation is several degrees, sufficient to enhance the hydrothermal stability of carbodiimide cross-linked AM materials. ${ }^{13}$ In this study, the thermal transitions of lysine-assisted EDC/NHS-cross-linked AM were investigated by differential scanning calorimetry (Figure 3). In the Lys0 groups, the shrinkage temperature was $71.3^{\circ} \mathrm{C} \pm 1.2^{\circ} \mathrm{C}$, and not significantly different from that of the Lys1 groups $\left(72.8^{\circ} \mathrm{C} \pm 1.6^{\circ} \mathrm{C} ; P>0.05\right)$, but was significantly lower than those of the Lys $3\left(76.1^{\circ} \mathrm{C} \pm 0.9^{\circ} \mathrm{C}\right)$, Lys 10 $\left(84.5^{\circ} \mathrm{C} \pm 1.4^{\circ} \mathrm{C}\right)$, and Lys $30\left(87.8^{\circ} \mathrm{C} \pm 1.6^{\circ} \mathrm{C}\right)$ groups $(P<0.05)$.

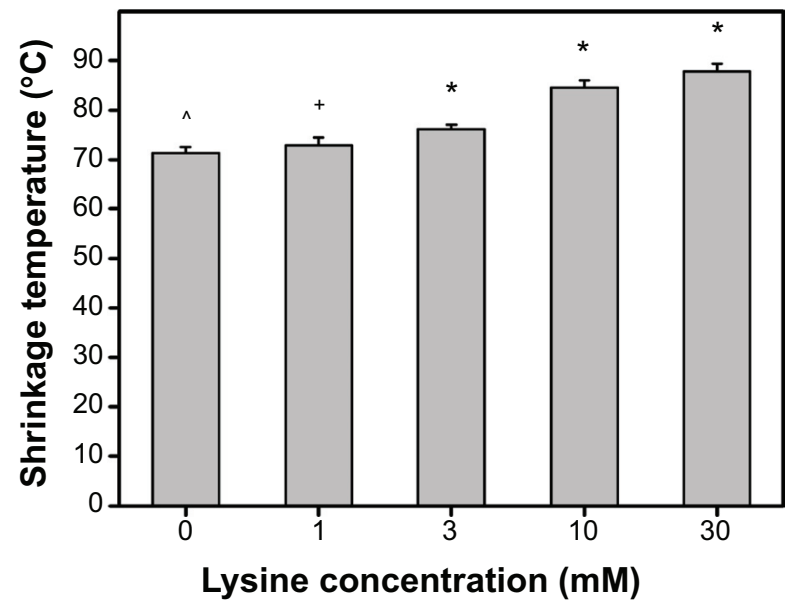

Figure 3 Shrinkage temperature of various amniotic membrane samples. Values are shown as the mean \pm standard deviation $(n=4)$.

Notes: ${ }^{* P}<0.05$ versus all groups; ${ }^{\wedge} P<0.05$ versus all groups except I mM; ${ }^{+P}<0.05$ versus all groups except $0 \mathrm{mM}$. 
These results indicate that a relatively low L-lysine-pretreated concentration does not affect the shrinkage behavior of nanofibrous collagen matrices. In addition, the variation in shrinkage temperature is in accordance with the results for the number of cross-links per unit mass of AM. In a previous report on the temperature-dependent kinetics of fibril formation, introduction of L-lysine along with the crosslinker among collagen fibers may lead to an increase in thermal stability. ${ }^{16}$ This may explain why a large amount of additional amino acid residue present in the AM is involved in the high shrinkage temperature of EDC/NHS-modified tissue collagen.

\section{In vitro degradation tests}

The AM collagen is susceptible to cleavage by collagenolytic enzymes, which are capable of causing scission of peptide bonds within the characteristic poly-L-proline type of helical regions in the molecules. ${ }^{39}$ It has been documented that both MMP-1 and MMP-9 play an essential role in degradation of the matrix in various inflammatory corneal diseases. ${ }^{40}$ Therefore, the residual mass percentage of various AM samples after 4 weeks of incubation in BSS containing these MMPs was recorded to evaluate the biological stability of the tissue collagen matrix. Figure 4 shows the in vitro enzymatic degradability of EDC/NHS-modified AM materials as a function of L-lysine-pretreated concentration. In the Lys0, Lys 1, and Lys3 groups, the remaining weight of the biological tissue membranes was significantly lower in the presence

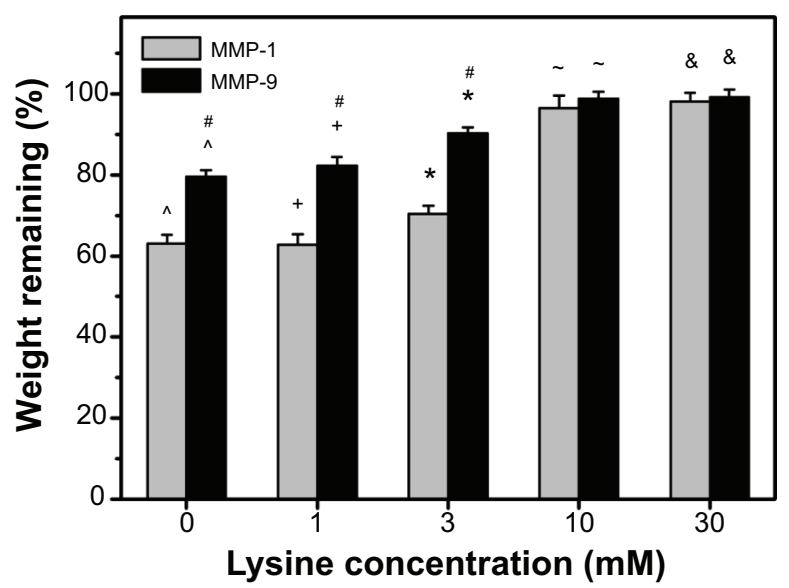

Figure 4 Weight remaining in various amniotic membrane samples after incubation at $37^{\circ} \mathrm{C}$ for 4 weeks in balanced salt solution containing MMP-I or MMP-9. Values are shown as the mean \pm standard deviation $(n=4)$.

Notes: ${ }^{*} P<0.05$ versus all groups; ${ }^{\wedge} P<0.05$ versus all groups except I mM; ${ }^{+} P<0.05$ versus all groups except $0 \mathrm{mM} ;-P<0.05$ versus all groups except $30 \mathrm{mM}$; ${ }^{\&} P<0.05$ versus all groups except $10 \mathrm{mM}$ (compared only within MMP-I or MMP-9 groups). ${ }^{\#} P<0.05$ indicates a statistically significant difference from the MMP-I group (compared only within each lysine concentration group).

Abbreviation: MMP, matrix metalloproteinase. of MMP-1 than in the presence of MMP-9 $(P<0.05)$. Given that each of these enzymes is reactive to a specific collagen type, the differences in tissue matrix degradation found here may be due to varied interactions between different MMPs and the structural components of AM collagen. Interestingly, when the L-lysine-pretreated concentration was increased to $10 \mathrm{mM}$, the remaining weight of the test samples did not show any significant difference between the MMP-1 (96.5\% $\pm 3.1 \%)$ and MMP-9 $(98.8 \% \pm 1.7 \%)$ groups $(P>0.05)$. In addition, there was almost no weight loss in the Lys30 group, irrespective of enzyme type. The findings of the current study suggest that the cross-linked structure of AM scaffolds constructed by a large amount of additional amino acid bridges seems to be sufficient to prevent the breakdown of protein molecules and degradation of the collagen network. The L-lysine pretreatment and the carbodiimide cross-linking-mediated change in enzyme-substrate binding may hinder attack by MMPs, thereby contributing to biological stabilization of nanofibrous tissue matrices for at least 4 weeks.

\section{Light transmittance measurements}

Transparency is a prerequisite for the development of useful ophthalmic biomaterials. Investigators have reported that the presence of AM grafts postoperatively may decrease optical transparency since these biological materials are thin, semi-transparent membranes. ${ }^{41}$ It is very important to determine the light transmission characteristics of AM scaffolds modified by L-lysine pretreatment and carbodiimide cross-linking. Figure 5 shows the results for optical transmittance measurements of various AM samples after incubation in $\mathrm{BSS}$ at $37^{\circ} \mathrm{C}$ for 6 hours. In the Lys 0 groups,

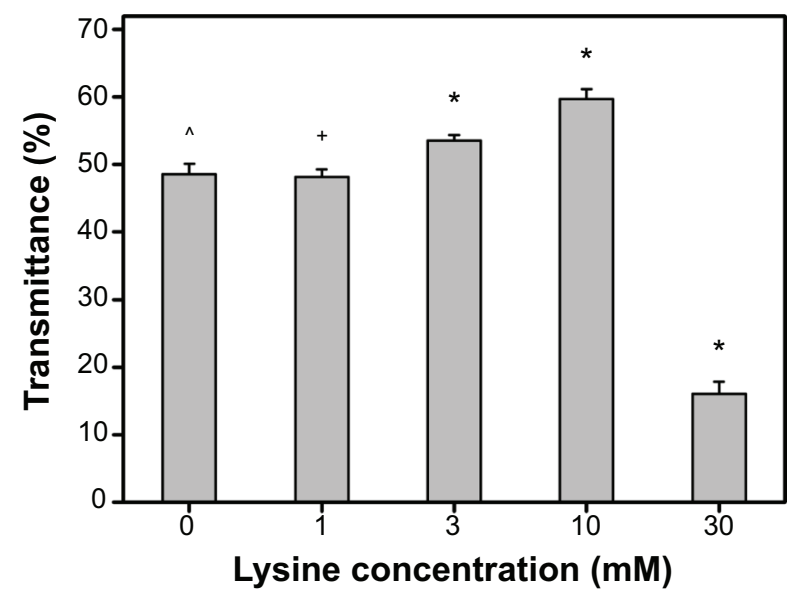

Figure 5 Optical transmittance of various amniotic membrane samples. Values are shown as the mean \pm standard deviation $(n=3)$.

Notes: ${ }^{*} P<0.05$ versus all groups; ${ }^{\wedge}<0.05$ versus all groups except I mM; ${ }^{+P}<0.05$ versus all groups except $0 \mathrm{mM}$. 
the average light transmittance of EDC/NHS-cross-linked biological tissue membranes was $48.6 \% \pm 1.5 \%$ in the wavelength range of 400-700 $\mathrm{nm}$. With increasing L-lysinepretreated concentration from 1 to $10 \mathrm{mM}$, the transmittance values significantly increased $(P<0.05)$. However, samples from the Lys30 groups had a reduced average transmittance of $16.0 \% \pm 1.8 \%$, which was even lower than that observed for fresh AM tissue. ${ }^{13}$ The results indicate that mild to moderate L-lysine pretreatment conditions facilitate light transmission through the carbodiimide cross-linked biological materials.

Since there is regional variability in the characteristics of donor AM, we collect the sample materials by cutting the biological tissues approximately $2 \mathrm{~cm}$ from the placental disc. Here, the test sample is approximately $100 \mu \mathrm{m}$ thick to avoid interference by tissue thickness in the light transmission measurements. For nanofibrous tissue scaffolds, the transparency is highly correlated with fiber size. ${ }^{42}$ Our previous study has shown that with increasing cross-linker concentration from 0.01 to $0.05 \mathrm{mmol} \mathrm{EDC} / \mathrm{mg}$ AM, cross-link formation leads to aggregation of collagen microfibrils and enlargement of interfibrillar spaces, thereby facilitating penetration of light into the AM. ${ }^{13}$ Surprisingly, when the cross-linker concentration is $0.25 \mathrm{mmol} \mathrm{EDC} / \mathrm{mg} \mathrm{AM}$, the chemically modified biological tissues exhibit poor optical properties. One possible explanation for these observations is that although the interfibrillar region becomes more pronounced, the assembled collagen fiber bundles are in the range of $1-2 \mu \mathrm{m}$ in diameter, which exceeds the longest wavelength of visible light (ie, $700 \mathrm{~nm}$ ). This interference factor may considerably decrease the optical transmittance. Therefore, to further investigate the effects of L-lysine pretreatment on the optical properties of EDC/NHS-cross-linked biological tissue membranes, the AM materials were characterized by transmission electron microscopy. As shown in Figure S1, the fiber diameter in the Lys 0 and Lys 1 groups was $424 \pm 39 \mathrm{~nm}$ and $458 \pm 45 \mathrm{~nm}$, respectively, with no significant difference $(P>0.05)$. For the scaffold samples modified by a large amount of L-lysine molecules, the increased number of cross-links per unit mass of AM led to more aggregation and formation of larger-sized nanofibers. In the Lys 10 groups, the fiber diameter was still below the threshold for the longest wavelength of visible light. Nevertheless, the tissue membranes from the Lys30 groups had an average fiber diameter above $700 \mathrm{~nm}$, thereby contributing to opacity. These findings indicate that light scattering by collagenous tissue materials is sensitive to the fibrillar ultrastructure. The results of this study provide the first evidence of a relationship between matrix transparency and nanofiber size controlled by lysine-assisted EDC/NHS cross-linking of AM.

\section{Cell viability assays}

Although cross-linking is able to improve the molecular stability of collagen, this process simultaneously leads to a change in the characteristics of biological materials and their consequent biocompatibility. By using HCE-2 cells (ie, a human corneal epithelial cell line), we investigated the cytocompatibility of lysine-assisted EDC/NHS-crosslinked AM. Figure 6 shows representative phase-contrast micrographs of HCE-2 cell cultures after incubation with various AM samples for 3 days. In the control and Lys0 groups, the cells presented similar growth patterns, indicating that exposure to carbodiimide cross-linked AM without L-lysine pretreatment does not damage human corneal epithelial cells. In the Lys1, Lys3, and Lys10 groups, the cultures also displayed a cobblestone-like morphology typical of normal corneal epithelial cells. However, in the Lys30 groups, a large percentage of surviving human corneal epithelial cells was observed, with noticeable cell death occurring. This result was also confirmed by live/ dead assays (Figure S2).

Figure 7 shows the results of a proliferation assay of human corneal epithelial cell cultures after a 3-day exposure to various AM samples. In the control groups, the mitochondrial dehydrogenase activity of cells in regular growth medium without contacting test materials was set to $100 \%$. No significant difference in activity levels was observed between the control and Lys0 groups $(P>0.05)$. In addition, upon exposure of HCE-2 cells to the AM scaffolds modified by L-lysine pretreatment and carbodiimide cross-linking, no significant reduction of MTS activity was detected in the Lys1 (98.7\% $\pm 0.8 \%)$, Lys3 $(98.4 \% \pm 1.4 \%)$, and Lys10 $(96.9 \% \pm 1.7 \%)$ groups $(P>0.05)$. In contrast, the measured activity level in the Lys30 groups was $91.3 \% \pm 1.0 \%$, which was significantly lower than that of the other groups $(P<0.05)$.

The findings of the current study suggest that in the presence of chemically cross-linked AM materials pretreated with varying concentrations of L-lysine $(0-10 \mathrm{mM})$, cultured HCE-2 cells exhibit corneal epithelial morphological characteristics with a normal proliferative capacity. These mild to moderate L-lysine pretreatment conditions do not affect in vitro biocompatibility of EDC/NHS cross-linked AM matrices. Nevertheless, the HCE- 2 cells exposed to the biological tissue membranes are less metabolically active when the L-lysine-pretreated concentration is increased to a sufficiently high level (ie, $30 \mathrm{mM}$ ). We have previously 


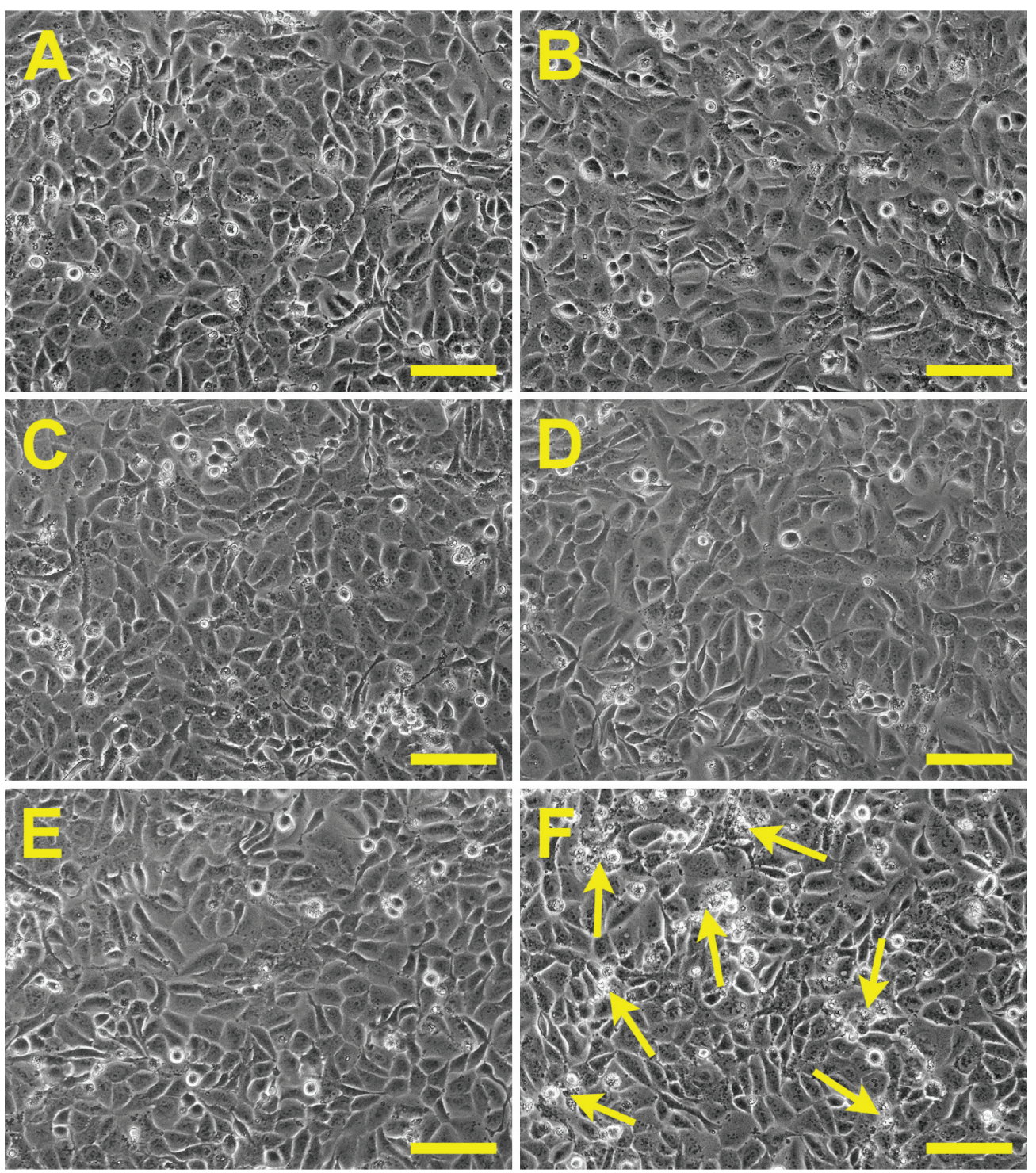

Figure 6 Phase-contrast micrographs of human corneal epithelial cell cultures.

Notes: The pattern of cell growth in (A) controls (without materials) after a 3-day exposure to various amniotic membrane samples. (B) Lys0, (C) Lys I, (D) Lys3, (E) Lys I0, and (F) Lys30. Dead cells (arrows) are presented in (F). Scale bars: $50 \mu \mathrm{m}$.

explored the relationship between the charge density of biomaterials and the proliferative capacity of various ocular cells, such as iris pigment epithelial cells, ${ }^{26}$ retinal pigment epithelial cells,${ }^{38}$ corneal stromal cells, ${ }^{19}$ and corneal endothelial cells..$^{43}$ For the test samples carrying either a positive or negative charge, the inhibition cell proliferation and decrease in cell viability are correlated with the relatively high charge density. As demonstrated by the aforementioned ninhydrin assays and zeta potential measurements, the presence of a large amount of positively charged amino acid residues in the AM pretreated with $30 \mathrm{mM}$ L-lysine causes reduction in cell survival over a period of 3 days, which indicates that these biological tissue membranes may not be well tolerated in human corneal epithelial cultures.

\section{Stemness gene and protein expression analyses}

In the field of corneal epithelial regenerative medicine research, the AM has been used as a niche that allows selfrenewal of limbal stem cells. ${ }^{44}$ To clarify the factors involving in the progenitor cell-preserving mechanism, our group has performed proteomic analysis and identified 13 proteins overexpressed by LECs cultured on AM substrates. ${ }^{45}$ After exposure to sublethal ultraviolet B irradiation or hydrogen peroxide, an increased apoptosis index and increased cleaved poly(ADP-ribose) polymerase formation are noted in heat shock protein 70-1-silenced, but not normal LECs, indicating the role of heat shock protein 70-1 in promoting LEC survival. Here, the effects of lysine-assisted EDC/NHS 


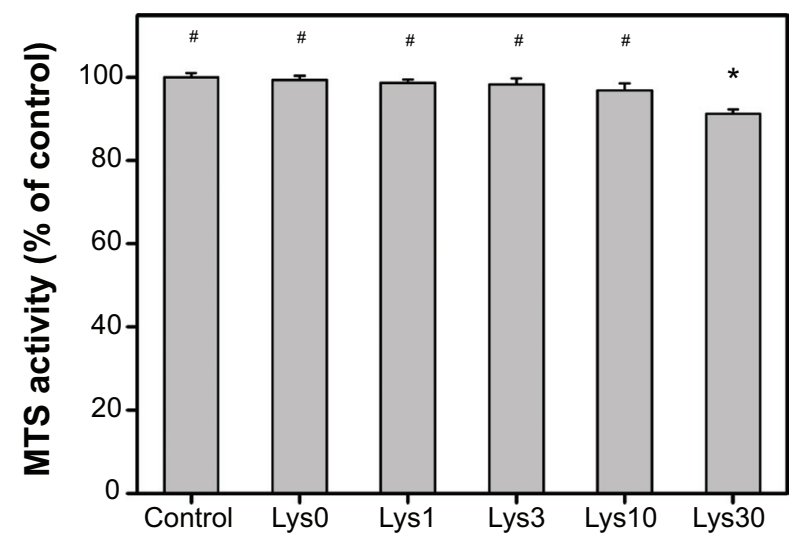

Figure 7 Cell proliferation assay of human corneal epithelial cell cultures after a 3-day exposure to various amniotic membrane samples. Results are expressed as a percentage of control values (MTS activity of cells cultured in the absence of materials). Values are shown as the mean \pm standard deviation $(n=4)$.

Notes: $* P<0.05$ versus all groups; ${ }^{\# P}<0.05$ versus $L y s 30$ groups.

Abbreviation: MTS, 3-(4,5-dimethylthiazol-2-yl)-5-(3-carboxymethoxyphenyl)-2(4-sulfophenyl)-2H-tetrazolium, inner salt.

cross-linking on the ability of AM to maintain the undifferentiated precursor cell phenotype were investigated. Both $\mathrm{p} 63$ and ABCG2 have been used as stem cell markers in limbal epithelium. ${ }^{13,14}$ Figure 8 presents the results for detection of stemness gene expression in rabbit LECs after 5 days of cultivation on various AM samples. Using quantitative real-time reverse transcription polymerase chain reaction, the measured transcript levels for p63 and the ABCG2 marker in the control groups (ie, cultures on tissue culture polystyrene in the absence of AM materials) were defined

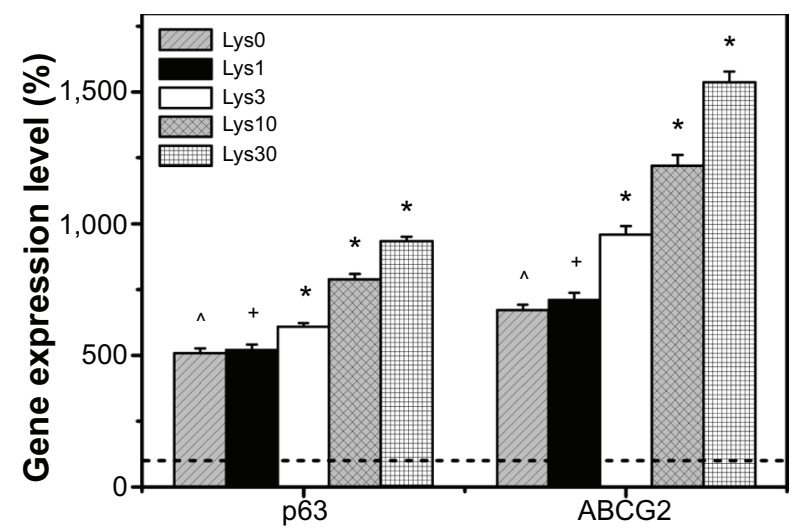

Figure 8 Gene expression levels for protein 63 and ABCG2 in rabbit limbal epithelial cells grown on various amniotic membrane samples for 5 days, measured by realtime reverse transcription polymerase chain reaction. Normalization was done using glyceraldehyde-3-phosphate dehydrogenase. Data in the experimental groups are percentages relative to those of the control groups (cells cultured on tissue culture polystyrene in the absence of amniotic membrane materials). The dashed line represents the detected expression level for each gene in the control groups (ie, defined as $100 \%)$. Values are shown as the mean \pm standard deviation $(n=4)$.

Notes: ${ }^{*} P<0.05$ versus all groups; ${ }^{\wedge} P<0.05$ versus all groups except Lys $1 ;{ }^{+} P<0.05$ versus all groups except Lys0.

Abbreviation: ABCG2, ATP binding cassette, subfamily G, member 2 . as $100 \%$. In the Lys0 groups, p63 gene expression was $507.1 \% \pm 18.4 \%$, which was significantly lower than those of the Lys3 $(608.6 \% \pm 13.7 \%)$, Lys $10(787.5 \% \pm 21.2 \%)$, and Lys30 $(934.3 \% \pm 16.9 \%)$ groups $(P<0.05)$. On the other hand, there was no significant difference in ABCG2 gene expression between the Lys0 $(672.4 \% \pm 20.5 \%)$ and Lys1 (710.6\% $\pm 26.8 \%)$ groups $(P>0.05)$. With increasing L-lysinepretreated concentration from 1 to $30 \mathrm{mM}$, levels of this marker increased significantly $(P<0.05)$. The findings of the current study suggest that AM scaffolds pretreated with a higher concentration of L-lysine may enhance the stemness of LECs during cultivation on carbodiimide cross-linked tissue collagen matrices.

Western blotting was also carried out to examine the correlation between stemness gene expression and protein expression. Figure 9A shows the results for detection of ABCG2 protein expression in rabbit LECs after 5 days of cultivation on various AM samples. Western blot analysis with an antibody for ABCG2 demonstrated a $70 \mathrm{kDa}$ band in these cell lysates. The protein expression patterns were similar in both the Lys 0 and Lys 1 groups. In contrast, the protein bands in the Lys3, Lys10, and Lys30 groups were more intense when compared with those of the other groups, indicating alteration of the stemness protein level in LECs grown on the EDC/NHS cross-linked AM scaffolds pretreated with a higher concentration of L-lysine.

A

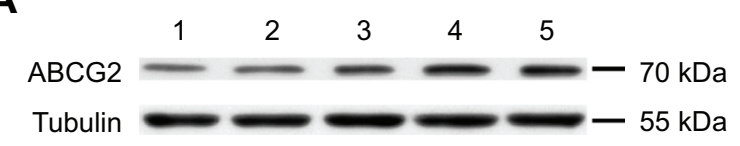

B

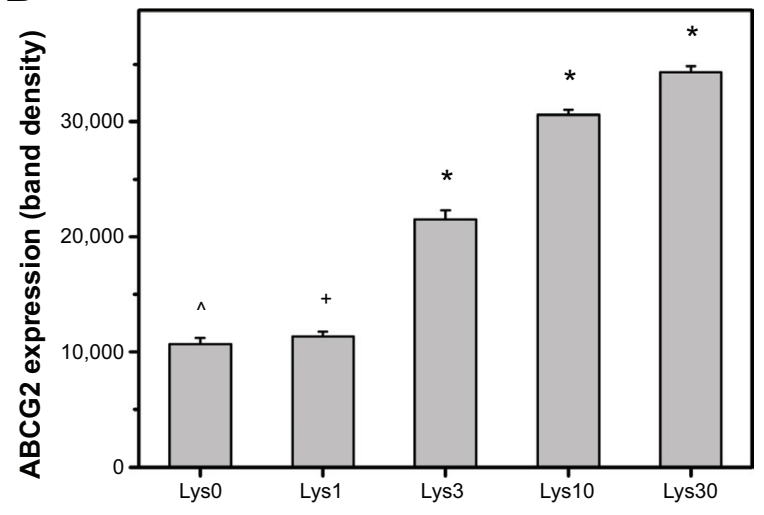

Figure 9 (A) Western blot analysis of ABCG2 expression in rabbit limbal epithelial cells grown on various amniotic membrane samples for 5 days. Lane I, Lys0; lane 2, Lys I; lane 3, Lys3; lane 4, Lys 10; lane 5, Lys30. (B) Intensity of ABCG2 relative to total protein measured by densitometry using Image] software. Values are shown as the mean \pm standard deviation $(n=4)$.

Notes: ${ }^{* P}<0.05$ versus all groups; ${ }^{\wedge} P<0.05$ versus all groups except $L y s I ;{ }^{+} P<0.05$ versus all groups except Lys0.

Abbreviation: ABCG2, ATP binding cassette, subfamily G, member 2 . 
Further quantitative analysis of protein signal intensity was performed by densitometry using ImageJ software (Figure 9B). The y axis reflects arbitrary density units. In the range of $1-30 \mathrm{mM}$, the ABCG2 expression level increased significantly with increasing L-lysine-pretreated concentration $(P<0.05)$. Our data demonstrate that the protein expression of ABCG2 on lysine-assisted carbodiimide cross-linked AM substrates follows the same trend as stemness gene expression.

The increased stemness gene and protein expression seen in this study indicates that AM substrates with more crosslinking can have a strong ability to maintain the undifferentiated precursor cell phenotype. Successful preservation of LEC progenitors depends directly on the stem cell niche. Levis et al have developed a simple one-step method to rapidly and reproducibly create bioengineered corneal limbal crypts in collagen hydrogel constructs, which are suitable for the growth of human LECs expressing a putative stem cell marker (ie, p63). ${ }^{46}$ In our study, the AM materials modified by L-lysine pretreatment and carbodiimide cross-linking are used to serve as stable stem cell niches for cultivation of LECs. For the first time, the regulation of stemness gene and protein expression in rabbit LECs was found to be dependent on the cross-linked structure of nanofibrous collagen matrices constructed by the incorporation of additional amino groups into AM scaffolds. With increasing L-lysine-pretreated concentration, the increase in the amount of amino acid bridges in these biological materials may promote cross-link formation and create a suitable microenvironment for preservation of progenitor LECs.

\section{Conclusion}

Stability and biocompatibility are both important factors that need to be taken into consideration when studying biomaterial cross-linking and its applications. Using L-lysine as an additional amino acid bridge, we investigated the stabilization of an EDC/NHS cross-linked AM collagen matrix for potential use as a limbal stem cell niche. Our results show that the amount of positively charged amino acid residues incorporated into the tissue collagen nanofibers is highly correlated with the L-lysine-pretreated concentration, thereby determining the cross-linked structure and hydrophilicity of scaffolding materials. The variations in thermal and biological stability are in accordance with the number of cross-links per unit mass of AM. It is noteworthy that the samples prepared using a relatively high L-lysine-pretreated concentration (ie, $30 \mathrm{mM}$ ) appear to have decreased light transmittance and cell viability, probably due to the effects of a large nanofiber size and high charge density. In the range of 1-30 $\mathrm{mM}$, the stemness gene and protein expression in LECs is upregulated with an increasing amount of amino acid bridges in the chemically cross-linked AM scaffolds. In summary, mild to moderate L-lysine pretreatment is a useful strategy to assist in the development of EDC/NHS cross-linked AM as a stable limbal stem cell niche.

\section{Acknowledgments}

This work was supported by the National Science Council of the Republic of China (grant NSC100-2628-E-182004-MY3). The author is grateful to Dr David Hui-Kang Ma (Department of Ophthalmology, Chang Gung Memorial Hospital) and Miss Hsiao-Yun Cheng (Molecular Medicine Research Center, Chang Gung University) for technical assistance.

\section{Disclosure}

The authors report no conflicts of interest in this work.

\section{References}

1. Har-el R, Tanzer ML. Extracellular matrix. 3: Evolution of the extracellular matrix in invertebrates. FASEB J. 1993;7:1115-1123.

2. Lai JY, Hsiue GH. Functional biomedical polymers for corneal regenerative medicine. React Funct Polym. 2007;67:1284-1291.

3. Mamede AC, Carvalho MJ, Abrantes AM, Laranjo M, Maia CJ, Botelho MF. Amniotic membrane: from structure and functions to clinical applications. Cell Tissue Res. 2012;349:447-458.

4. Tsai RJF, Li LM, Chen JK. Reconstruction of damaged corneas by transplantation of autologous limbal epithelial cells. N Engl J Med. 2000; 343:86-93.

5. Slansky HH, Dohlman CH. Collagenase and the cornea. Surv Ophthalmol. 1970;14:402-415.

6. Spoerl E, Wollensak G, Reber F, Pillunat L. Cross-linking of human amniotic membrane by glutaraldehyde. Ophthalmic Res. 2004;36:71-77.

7. Fujisato T, Tomihata K, Tabata Y, Iwamoto Y, Burczak K, Ikada Y. Cross-linking of amniotic membranes. J Biomater Sci Polym Ed. 1999;10: 1171-1181.

8. Lai JY, Ma DHK. Glutaraldehyde cross-linking of amniotic membranes affects their nanofibrous structures and limbal epithelial cell culture characteristics. Int J Nanomedicine. 2013;8:4157-4168.

9. Lai JY. Interrelationship between cross-linking structure, molecular stability, and cytocompatibility of amniotic membranes cross-linked with glutaraldehyde of varying concentrations. RSC Adv. 2014;4: $18871-18880$

10. Lai JY, Li YT. Influence of cross-linker concentration on the functionality of carbodiimide cross-linked gelatin membranes for retinal sheet carriers. J Biomater Sci Polym Ed. 2011;22:277-295.

11. Lai JY. Evaluation of cross-linking time for porous gelatin hydrogels on cell sheet delivery performance. J Mech Med Biol. 2011;11:967-981.

12. Lai JY, Li YT. Functional assessment of cross-linked porous gelatin hydrogels for bioengineered cell sheet carriers. Biomacromolecules. 2010; 11:1387-1397.

13. Ma DHK, Lai JY, Cheng HY, Tsai CC, Yeh LK. Carbodiimide crosslinked amniotic membranes for cultivation of limbal epithelial cells. Biomaterials. 2010;31:6647-6658.

14. Lai JY, Lue SJ, Cheng HY, Ma DHK. Effect of matrix nanostructure on the functionality of carbodiimide cross-linked amniotic membranes as limbal epithelial cell scaffolds. J Biomed Nanotechnol. 2013;9: 2048-2062. 
15. Ma L, Gao C, Mao Z, Zhou J, Shen J. Enhanced biological stability of collagen porous scaffolds by using amino acids as novel cross-linking bridges. Biomaterials. 2004;25:2997-3004.

16. Usha R, Sreeram KJ, Rajaram A. Stabilization of collagen with EDC/ NHS in the presence of L-lysine: a comprehensive study. Colloids Surf B Biointerfaces. 2012;90:83-90.

17. Lu PL, Lai JY, Tabata Y, Hsiue GH. A methodology based on the "anterior chamber of rabbit eyes" model for noninvasively determining the biocompatibility of biomaterials in an immune privileged site. J Biomed Mater Res A. 2008;86:108-116.

18. Lai JY, Li YT. Evaluation of cross-linked gelatin membranes as delivery carriers for retinal sheets. Mater Sci Eng C. 2010;30:677-685.

19. Lai JY. Effect of chemical composition on corneal cellular response to photopolymerized materials comprising 2-hydroxyethyl methacrylate and acrylic acid. Mater Sci Eng C. 2013;33:3704-3710.

20. Lai JY, Wang TP, Li YT, Tu IH. Synthesis, characterization and ocular biocompatibility of potential keratoprosthetic hydrogels based on photopolymerized poly(2-hydroxyethyl methacrylate)-co-poly(acrylic acid). J Mater Chem. 2012;22:1812-1823.

21. Lai JY. Biocompatibility of chemically cross-linked gelatin hydrogels for ophthalmic use. J Mater Sci Mater Med. 2010;21:1899-1911.

22. Lai JY, Hsieh AC. A gelatin- $g$-poly( $N$-isopropylacrylamide) biodegradable in situ gelling delivery system for the intracameral administration of pilocarpine. Biomaterials. 2012;33:2372-2387.

23. Lai JY, Li YT, Cho CH, Yu TC. Nanoscale modification of porous gelatin scaffolds with chondroitin sulfate for corneal stromal tissue engineering. Int J Nanomedicine. 2012;7:1101-1114.

24. Lai JY. Biodegradable in situ gelling delivery systems containing pilocarpine as new antiglaucoma formulations: effect of a mercaptoacetic acid/ $N$-isopropylacrylamide molar ratio. Drug Des Devel Ther. 2013; 7:1273-1285.

25. Lai JY, Tu IH. Adhesion, phenotypic expression, and biosynthetic capacity of corneal keratocytes on surfaces coated with hyaluronic acid of different molecular weights. Acta Biomater. 2012;8:1068-1079.

26. Lai JY, Lin PK, Hsiue GH, Cheng HY, Huang SJ, Li YT. Low Bloom strength gelatin as a carrier for potential use in retinal sheet encapsulation and transplantation. Biomacromolecules. 2009;10:310-319.

27. Lai JY. Relationship between structure and cytocompatibility of divinyl sulfone cross-linked hyaluronic acid. Carbohydr Polym. 2014;101: 203-212.

28. Lai JY, Chen KH, Hsiue GH. Tissue-engineered human corneal endothelial cell sheet transplantation in a rabbit model using functional biomaterials. Transplantation. 2007;84:1222-1232.

29. Dua HS, Gomes JA, King AJ, Maharajan VS. The amniotic membrane in ophthalmology. Surv Ophthalmol. 2004;49:51-77.

30. Niknejad H, Peirovi H, Jorjani M, Ahmadiani A, Ghanavi J, Seifalian AM. Properties of the amniotic membrane for potential use in tissue engineering. Eur Cell Mater. 2008;15:88-99.

31. Jezova D, Makatsori A, Smriga M, Morinaga Y, Duncko R. Subchronic treatment with amino acid mixture of L-lysine and L-arginine modifies neuroendocrine activation during psychosocial stress in subjects with high trait anxiety. Nutr Neurosci. 2005;8:155-160.
32. Fujiwara K, Ramesh A, Maki T, Hasegawa H, Ueda K. Adsorption of platinum (IV), palladium (II) and gold (III) from aqueous solutions onto L-lysine modified crosslinked chitosan resin. J Hazard Mater. 2007; 146:39-50.

33. Li WC, Lee SW. The characteristics of lysine-mediated self-assembly of gold nanoparticles on the ITO glass. Curr Appl Phys. 2012;12: 1361-1365.

34. Olde Damink LH, Dijkstra PJ, van Luyn MJ, van Wachem PB, Nieuwenhuis P, Feijen J. Cross-linking of dermal sheep collagen using a water-soluble carbodiimide. Biomaterials. 1996;17:765-773.

35. Highberger JH. The isoelectric point of collagen. J Am Chem Soc. 1939 ; 61:2302-2303

36. Lai JY, Ma DHK, Lai MH, Li YT, Chang RJ, Chen LM. Characterization of cross-linked porous gelatin carriers and their interaction with corneal endothelium: biopolymer concentration effect. PLoS One. 2013;8:e54058.

37. Lu PL, Lai JY, Ma DHK, Hsiue GH. Carbodiimide cross-linked hyaluronic acid hydrogels as cell sheet delivery vehicles: characterization and interaction with corneal endothelial cells. J Biomater Sci Polym Ed. 2008;19:1-18.

38. Lai JY. The role of Bloom index of gelatin on the interaction with retinal pigment epithelial cells. Int J Mol Sci. 2009;10:3442-3456.

39. Harper E, Berger A, Katchalski E. The hydrolysis of poly (L-ProlylGlycyl-L-Prolyl) by bacterial collagenase. Biopolymers. 1972;11: 1607-1612.

40. Sivak JM, Fini ME. MMPs in the eye: emerging roles for matrix metalloproteinases in ocular physiology. Prog Retin Eye Res. 2002;21: $1-14$.

41. Yang J, Yamato M, Kohno C, et al. Cell sheet engineering: recreating tissues without biodegradable scaffolds. Biomaterials. 2005;26: 6415-6422.

42. Freund DE, McCally RL, Farrell RA, Cristol SM, L'Hernault NL, Edelhauser HF. Ultrastructure in anterior and posterior stroma of perfused human and rabbit corneas. Relation to transparency. Invest Ophthalmol Vis Sci. 1995;36:1508-1523.

43. Lai JY, Lu PL, Chen KH, Tabata Y, Hsiue GH. Effect of charge and molecular weight on the functionality of gelatin carriers for corneal endothelial cell therapy. Biomacromolecules. 2006;7:1836-1844.

44. Grueterich M, Espana EM, Tseng SCG. Ex vivo expansion of limbal epithelial stem cells: amniotic membrane serving as a stem cell niche. Surv Ophthalmol. 2003;48:631-646.

45. Ma DHK, Lai JY, Yu ST, et al. Up-regulation of heat shock protein 70-1 (Hsp70-1) in human limbo-corneal epithelial cells cultivated on amniotic membrane: a proteomic study. J Cell Physiol. 2012;227: 2030-2039.

46. Levis HJ, Massie I, Dziasko MA, Kaasi A, Daniels JT. Rapid tissue engineering of biomimetic human corneal limbal crypts with 3D niche architecture. Biomaterials. 2013;34:8860-8868. 


\section{Supplementary materials}

Materials and methods

\section{Transmission electron microscopy}

For transmission electron microscopy (TEM) studies, the AM samples were fixed in osmium tetroxide and dehydrated in a graded series of ethanol solutions. After infiltration with Spurr's resin, the tissue specimens were cut into blocks with a width of $1 \mathrm{~mm}$, placed in flat embedding molds, and polymerized at $70^{\circ} \mathrm{C}$ overnight. Ultrathin sections were cut using a diamond knife on a Reichert Ultracut S microtome (Leica Microsystems, Wetzlar, Germany), stained with $2 \%$ uranyl acetate, and visualized using a JEM-1230 TEM (Jeol, Tokyo, Japan). For each tissue sample, five randomly chosen fields were counted at $30,000 \times$ magnification and

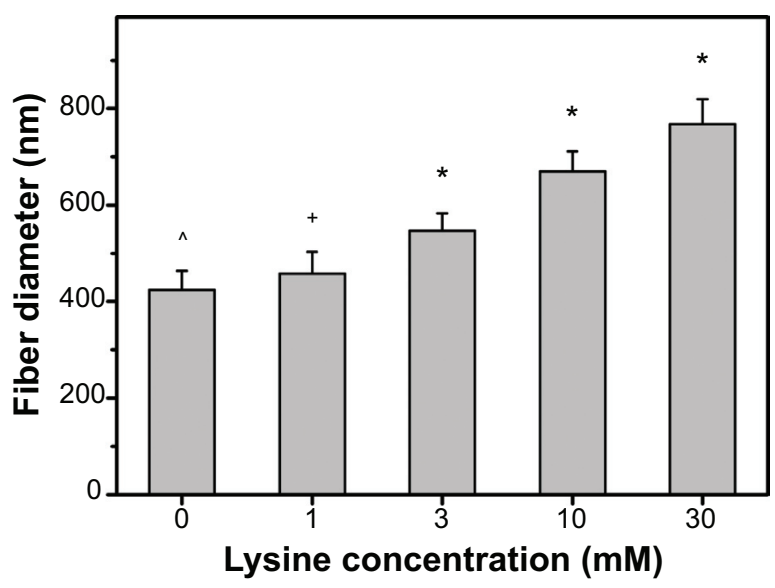

Figure SI Fiber diameter of various AM samples. Values are mean \pm standard deviation $(n=3)$.

Notes: ${ }^{* P}<0.05$ vs all groups; ${ }^{\wedge} P<0.05$ vs all groups except I mM; ${ }^{+P}<0.05$ vs all groups except $0 \mathrm{mM}$.

Abbreviation: AM, amniotic membrane. the diameter of 200 collagen fibrils was measured with the microscope. Results were the average of three independent experiments.

\section{Live/dead assays}

Cytotoxicity was determined using a membrane integrity assay, the live/dead viability/cytotoxicity kit (Molecular Probes, Eugene, OR, USA) which contains calcein acetoxymethyl and ethidium homodimer-1. At 3 days of incubation with AM samples from Lys30 groups, the cultures were stained with a working solution consisting of $2 \mu \mathrm{L}$ of ethidium homodimer- $1,1 \mathrm{~mL}$ of PBS, and $0.5 \mu \mathrm{L}$ of calcein acetoxymethyl, and viewed under fluorescence microscopy (Axiovert 200M; Carl Zeiss, Oberkochen, Germany).

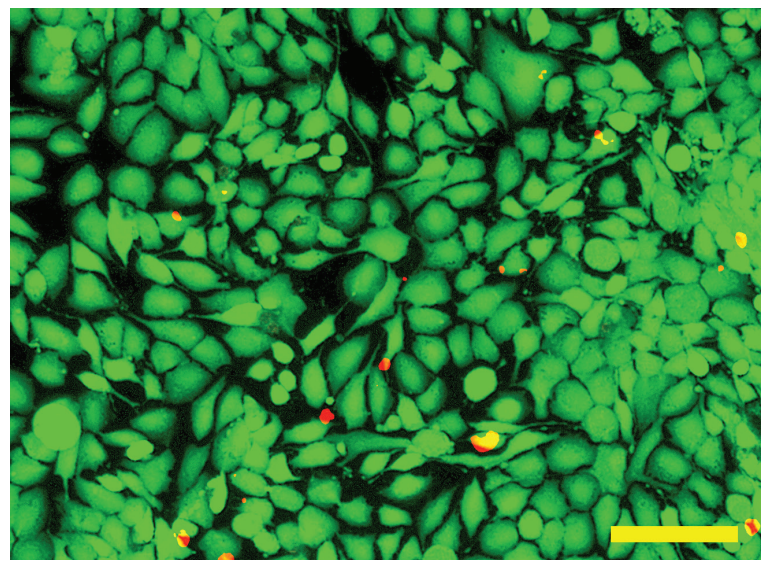

Figure S2 Cell viability of human corneal epithelial cell cultures was determined by staining with a live/dead viability/cytotoxicity kit in which the live cells fluoresce green and the dead cells fluoresce red. Fluorescence image of cells after a 3-day exposure to AM sample Lys30. Scale bars: $50 \mu \mathrm{m}$.

Abbreviation: AM, amniotic membrane.

\section{Publish your work in this journal}

The International Journal of Nanomedicine is an international, peerreviewed journal focusing on the application of nanotechnology in diagnostics, therapeutics, and drug delivery systems throughout the biomedical field. This journal is indexed on PubMed Central, MedLine, CAS, SciSearch ${ }^{\circledR}$, Current Contents ${ }^{\circledR} /$ Clinical Medicine,

Journal Citation Reports/Science Edition, EMBase, Scopus and the Elsevier Bibliographic databases. The manuscript management system is completely online and includes a very quick and fair peer-review system, which is all easy to use. Visit http://www.dovepress.com/ testimonials.php to read real quotes from published authors. 